\title{
The incorporation of
}

\section{linolenic and linoleic acids into the plasma lipids of sheep given intra-abomasal infusions of linseed oil, maize oil or linoleic acid}

\author{
By J. H. MOORE, R. C. NOBLE ANd W. STEELE \\ Hannah Dairy Research Institute, Ayr
}

(Received 8 fuly r968-Accepted 8 October I968)

\begin{abstract}
I. The fatty acid compositions of the plasma cholesteryl esters, phospholipids, triglycerides and unesterified fatty acids were determined in three sheep at various times after they had been given intra-abomasal infusions of emulsions of linseed oil, maize oil or linoleic acid.

2. The concentrations of linolenic acid or linoleic acid in the plasma triglycerides began to increase $\mathrm{I} \cdot \mathrm{s} \mathrm{h}$ after infusion of the emulsions had begun. As the concentration of linolenic or linoleic acids in the plasma triglycerides increased, the concentrations of palmitic and stearic acids decreased, but there were no appreciable changes in the concentrations of oleic acid.

3. The concentrations of linolenic or linoleic acid in the plasma phospholipids and cholesteryl esters did not begin to increase until 8-9h and $24-25 \mathrm{~h}$ respectively after the infusions of the emulsions had begun.

4. It is suggested that, after absorption from the small intestine of the sheep, linolenic and linoleic acids are transported in triglyceride form to the liver where the triglycerides are partially or completely hydrolysed. These $C_{18}$ polyunsaturated acids are then preferentially utilized for the synthesis of phospholipids and cholesteryl esters but not for the re-synthesis of triglycerides.
\end{abstract}

In a previous investigation with sheep (Moore, Noble \& Steele, I968) it was observed that when a diet of hay was replaced by one of dried grass, there was an increase in the concentration of linolenic acid and a decrease in the concentration of linoleic acid in the plasma cholesteryl esters and phospholipids, but there were no significant effects on the concentrations of these $C_{18}$ polyunsaturated fatty acids in the plasma triglycerides or unesterified fatty acids. The linoleic:linolenic acid ratios in the hay and dried grass were 1.40 and 0.64 respectively. In a further experiment (Moore et al. I968), it was found that when sheep were given daily intraruminal infusions of linolenic or linoleic acids over a period of 5 days, there were increases in the concentrations of linolenic or linoleic acids in the plasma cholesteryl esters and phospholipids. Again, no significant effects were observed on the concentrations of linolenic or linoleic acids in the plasma triglycerides or unesterified fatty acids. Thus, in spite of the extensive hydrogenation of dietary polyunsaturated fatty acids that is thought to occur in the rumen (e.g. see Tove \& Mochrie, r963), it would appear that the polyunsaturated fatty acid composition of the diet does exert some influence on the composition of the polyunsaturated fatty acids in certain of the lipid fractions in the plasma of sheep. It is possible that a certain proportion of the dietary polyunsaturated fatty acids escape hydrogenation in the rumen and pass on to be absorbed from the small intestine. If so, and if the mechanism of the absorption of fatty acids is the same as that in monogastric animals (Senior, 1964), then it is difficult 
to account for the fact that the experimental treatments described by Moore et al. (I968) did not affect the polyunsaturated fatty acid composition of the plasma triglycerides of the sheep. To investigate this problem in greater detail, the fatty acid compositions of the various plasma lipids have been determined at various times after sheep had been given intra-abomasal infusions of linseed oil, maize oil or linoleic acid. Hydrogenation of the administered polyunsaturated fatty acids in the rumen was thereby avoided. The results of this investigation are now reported.

\section{EXPERIMENTAL}

\section{Animals and diets}

Three adult wether sheep (mean weight, $65 \mathrm{~kg}$ ) of the Hampshire breed, each with a permanent abomasal fistula, were housed in individual metabolism cages. For a period of 3 weeks before the experiment began, the sheep were given a diet consisting entirely of hay. Each sheep was given $900 \mathrm{~g}$ hay/day in two equal portions, one at $07.00 \mathrm{~h}$ and one at $16.00 \mathrm{~h}$. The fatty acid composition of the hay is given in Table I, During the preliminary period and during the experiments, the sheep were given water ad lib.

\section{Procedure}

Expt I. On the day the experiment began, sheep no. I was given a meal of $450 \mathrm{~g}$ hay at $07.00 \mathrm{~h}$. Between $09.00 \mathrm{~h}$ and $10.00 \mathrm{~h}$ an emulsion of $40 \mathrm{~g}$ of linseed oil was infused at constant rate into the abomasum of the sheep. The fatty acid composition of the linseed oil is given in Table I together with the compositions of the maize oil and linoleic acid used in Expts 2 and 3 . The emulsion was prepared by homogenizing $40 \mathrm{~g}$ linseed oil with $60 \mathrm{ml}$ of $1 \cdot 0 \%(\mathrm{w} / \mathrm{v})$ Tween 80 (polyoxyethylene sorbitan mono-oleate, obtained from Honeywill \& Stein Ltd, London) and was administered by means of an infusion pump (Distillers' Company Ltd, Epsom, Surrey). With a solution of trisodium citrate dihydrate $(3.8 \%, \mathrm{w} / \mathrm{v})$ as an anticoagulant, blood samples ( $10-15 \mathrm{ml}$ ) were taken immediately before and at various time intervals (see Table 2) after the intra-abomasal infusion of linseed oil had begun. The sheep was given the second half of its daily ration of hay at $\mathrm{I} 6.00 \mathrm{~h}$, i.e. $7 \mathrm{~h}$ after the start of the infusion of linseed oil. On the following day, the sheep was fed at $07.00 \mathrm{~h}$, i.e. $22 \mathrm{~h}$ after the infusion of linseed oil was begun. The last blood sample was taken $2 \mathrm{~h}$ later, i.e. $24 \mathrm{~h}$ after the start of the infusion of linseed oil.

Expt 2. On the day the experiment began, sheep no. 2 was given a meal of $45^{\circ} \mathrm{g}$ hay at $07.00 \mathrm{~h}$. Between $09.00 \mathrm{~h}$ and $10.00 \mathrm{~h}$ the sheep was given an intra-abomasal infusion of an emulsion of $40 \mathrm{~g}$ of maize oil. The emulsion of maize oil was prepared as described for the emulsion of linseed oil in Expt I. As in Expt I, blood samples were taken from the jugular vein of the sheep immediately before and at various time intervals (see Table 4 ) after the intra-abomasal infusion of maize oil had begun. However, in contrast to Expt I, food was withheld from the sheep until the last blood sample was taken $24 \mathrm{~h}$ after the start of the infusion of maize oil.

Expt 3. On the Ist day of the experiment, sheep no. 3 was given the first half of its daily ration of hay at $19.00 \mathrm{~h}$. Between $09.00 \mathrm{~h}$ and $10.00 \mathrm{~h}$ the sheep was given an 
intra-abomasal infusion of an emulsion of $60 \mathrm{~g}$ of linoleic acid (obtained from Price's (Bromborough) Ltd, Bebington, Cheshire). The emulsion of linoleic acid was prepared by homogenizing $60 \mathrm{~g}$ of linoleic acid with $40 \mathrm{ml}$ of $\mathrm{I} \%(\mathrm{w} / \mathrm{v})$ Tween 80. As in Expts I and 2, blood samples were taken from the jugular vein of the sheep immediately before and at various time intervals (see Table 6) after the intra-abomasal infusion of linoleic acid had begun. On the Ist day of the experiment the sheep was not given the second half of its daily ration of hay until $22.00 \mathrm{~h}$, i.e. I $3 \mathrm{~h}$ after the start of the infusion of linoleic acid. On the 2 nd and 3 rd days of the experiment, the sheep was fed normally, i.e. at $07.00 \mathrm{~h}$ and $\mathrm{I} 6.00 \mathrm{~h}$. The last blood sample was taken

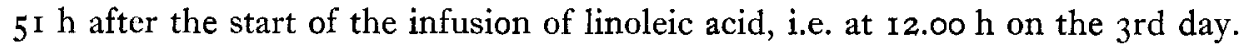

\section{Extraction of lipids and methods of analysis}

The fatty acid composition of the hay was determined as described by Moore $\&$ Williams (1963). The lipids were extracted from the samples of plasma by the method of Nelson \& Freeman (1959). The fatty acid compositions of the plasma cholesteryl esters, triglycerides, unesterified fatty acids and phospholipids were determined by methods described in detail by Moore \& Williams (r964), Noble \& Moore (I964) and Moore et al. (1968). Throughout this paper the shorthand designation proposed by Farquhar, Insull, Rosen, Stoffel \& Ahrens (1959) is used to denote individual fatty acids. Owing to the small amount of lipid extracted from each sample of plasma, no attempt was made to determine the absolute concentrations of the various lipid fractions in the plasma but the lipid extracts were examined qualitatively by thin-layer chromatography as described by Mangold (I96I).

\section{RESULTS}

Expt I. Assessment of variations in the proportions of the individual lipid fractions in the plasma samples was limited to qualitative examinations of thin-layer chromatograms of the plasma lipids. In the plasma samples obtained before and immediately

Table 1 . Compositions of the fatty acids (major components, weight percentages of the total) present in the hay, linseed oil, maize oil and linoleic acid

\begin{tabular}{|c|c|c|c|c|}
\hline Fatty acid & Hay & Linseed oil & Maize oil & 'Linoleic acid' \\
\hline I6:0 & $20 \cdot 7$ & -- & $9 \cdot 9$ & 15.2 \\
\hline 16:1 & $2 \cdot 2$ & - & 一 & $0 \cdot 3$ \\
\hline 18:0 & $5 \cdot 6$ & - & $2 \cdot I$ & $2 \cdot 2$ \\
\hline I $8: 1$ & 18.9 & $7 \cdot 6$ & $22 \cdot 9$ & 10.9 \\
\hline $18: 2$ & 25.0 & $2 \pi \cdot 3$ & 64.4 & $7 x \cdot I$ \\
\hline $18: 3$ & $17 \cdot 8$ & $7 I \cdot 1$ & 0.7 & $\longrightarrow$ \\
\hline
\end{tabular}

after the start of infusion of linseed oil, it was clear that cholesteryl esters and phospholipids were the major component of the plasma lipids; triglycerides and unesterified fatty acids were relatively minor components. However, the proportion of triglycerides in the total lipid was markedly increased in the plasma samples obtained 4, 6, 8 and to $h$ after infusion began. The relative proportions of the various 
plasma lipid fractions in the sample obtained $24 \mathrm{~h}$ after infusion began were similar to those in the sample obtained before infusion began.

The fatty acid compositions of the plasma triglycerides and unesterified fatty acids in the samples of blood taken before and at various times after the start of infusion of linseed oil into the abomasum of sheep no. $\mathrm{I}$ are given in Table 2. Only trace concentrations of $\mathrm{I} 8: 3$ were found in the plasma triglycerides obtained before and 0.5 and $\mathrm{I} \mathrm{h}$ after the start of infusion. Thereafter, there was a pronounced increase in the concentration of $18: 3$ in the plasma triglycerides but two distinct concentration

Table 2. Effect of the infusion of an emulsion of linseed oil into the abomasum of a sheep on the fatty acid composition (major components, weight percentages of the total) of the plasma triglycerides and unesterified fatty acids

\begin{tabular}{|c|c|c|c|c|c|c|c|c|c|c|c|c|}
\hline \multirow{2}{*}{$\begin{array}{l}\text { Time } \\
\text { after } \\
\text { begin- } \\
\text { ning of } \\
\text { infusion } \\
\text { (h) }\end{array}$} & \multicolumn{6}{|c|}{ Triglycerides } & \multicolumn{6}{|c|}{ Unesterified fatty acids } \\
\hline & $16: 0$ & I6: I & 18:0 & I $8: 1$ & I $8: 2$ & $18: 3$ & $16: 0$ & $16: x$ & I 8:0 & I $8:$ I & $18: 2$ & $18: 3$ \\
\hline 0 & $37 \cdot 6$ & I $\cdot 8$ & $25^{\prime} 1$ & $22 \cdot 5$ & $4 \cdot 7$ & - & $25 \cdot 1$ & $5 \cdot 4$ & $25 \cdot 6$ & $39 \cdot 5$ & $I \cdot 3$ & - \\
\hline 0.5 & $3^{8 \cdot 6}$ & $1 \cdot 4$ & $28 \cdot 5$ & $21 \cdot 0$ & $3 \cdot r$ & - & $17 \cdot 7$ & $3 \cdot 4$ & $33^{\circ} 0$ & 43.9 & $I \cdot 4$ & -- \\
\hline$I \cdot 0$ & $40 \cdot 8$ & $1 \cdot 4$ & 25.9 & $22 \cdot 5$ & 3.5 & 一 & $24 \cdot 8$ & $2 \cdot 8$ & $34^{\cdot 2}$ & $35 \cdot 7$ & $I \cdot 4$ & - \\
\hline $1 \cdot 5$ & $30 \cdot 4$ & $I \cdot 4$ & 23.4 & $25 \cdot 6$ & $5 \cdot 0$ & $4 \cdot 1$ & $23 \cdot 6$ & $6 \cdot 2$ & $29 \cdot 6$ & $37 \circ$ & $2 \cdot 5$ & 0 \\
\hline 2.0 & $27 \cdot 1$ & I. 5 & 19.5 & $23 \cdot 8$ & $5 \cdot I$ & $12 \cdot 2$ & $25 \cdot 3$ & $6 \cdot 9$ & $32 \cdot 5$ & $25 \cdot 1$ & $2 \cdot 9$ & $2 \cdot 8$ \\
\hline $3 \cdot 0$ & $15 \cdot 5$ & $\mathrm{I} \cdot 5$ & $x I \cdot 3$ & $24 \cdot 6$ & $I I \cdot 3$ & $3 I \cdot 4$ & 20.4 & $3 \cdot 3$ & 18.0 & 30.8 & 13.9 & $9 \cdot 3$ \\
\hline 4.0 & 14.1 & $I \cdot 3$ & $9 \cdot 2$ & $23 \cdot 6$ & 12.4 & 33.9 & 17.6 & $3 \cdot 5$ & $22 \cdot 0$ & 30.6 & $9^{\circ} \mathbf{I}$ & I 1.8 \\
\hline 6.0 & 20.2 & 1.5 & $12 \cdot 1$ & 25.9 & II 7 & $24 \cdot 6$ & $2 \mathrm{I} \cdot 9$ & $3 \cdot 3$ & $33^{\cdot I}$ & 29.0 & 3.9 & $8 \cdot 9$ \\
\hline 8.0 & 18.0 & $I .6$ & II. 5 & $24 \cdot I$ & II 9 & $29^{\circ} 0$ & $17 \cdot 7$ & $3 \cdot 6$ & 30.1 & $29^{\prime} \mathrm{I}$ & $4 \cdot 5$ & $\mathrm{r}_{4} \cdot \mathrm{I}$ \\
\hline 10.0 & 16.0 & 0.8 & 10.0 & 23.7 & $\mathrm{II} \cdot 4$ & 35.4 & 17.5 & $6 \cdot I$ & $26 \cdot 5$ & $28 \cdot 0$ & $6 \cdot 1$ & 15.3 \\
\hline 24.0 & $40 \cdot I$ & $2 \cdot I$ & $22 \cdot 9$ & 20.0 & $4^{\circ} 0$ & 4.8 & $24 \cdot 6$ & $6 \cdot 9$ & 25.9 & $37 \cdot 7$ & 2.0 & I. \\
\hline
\end{tabular}

peaks were observed, one $4 \mathrm{~h}$ and the other io $\mathrm{h}$ after the start of infusion. In this respect, it should be remembered that sheep no. $x$ was given the second half of its daily ration of hay at 16.00 h, i.e. $7 \mathrm{~h}$ after infusion started. In the blood sample taken $24 \mathrm{~h}$ after infusion started, the concentration of $18: 3$ in the plasma triglycerides had fallen to less than $5 \%$. For the first $2 \mathrm{~h}$ after the beginning of infusion, the concentration of $18: 2$ in the plasma triglycerides was similar to that observed in the pre-infusion sample, but between 2 and $3 \mathrm{~h}$ after infusion started the concentration of $18: 2$ in the plasma triglycerides was doubled. During the following $7 \mathrm{~h}$ the concentration of $18: 2$ in the plasma triglycerides remained relatively constant but then decreased to pre-infusion levels in the sample taken $24 \mathrm{~h}$ after infusion began. Since the linseed oil contained $72 \% 18: 3$ and only $22 \% 18: 2$ it was not surprising to find that the concentration of $18: 3$ in the plasma triglycerides increased to higher levels than did the concentration of $18: 2$. There were no marked changes in the concentration of $18: \mathrm{I}$ in the plasma triglycerides.

Changes in the concentration of $18: 3$ in the plasma unesterified fatty acids were similar to the changes in the concentration of $\mathrm{I} 8: 3$ observed in the plasma triglycerides; peak concentrations occurred 4 and to $h$ after the start of infusion. However, the concentrations of $18: 3$ in the unesterified fatty acids were always considerably less 
than the corresponding concentrations of $18: 3$ in the plasma triglycerides. On the other hand, changes in the concentration of $18: 2$ in the plasma unesterified fatty acids were somewhat different from the changes in the concentration of $18: 2$ in the plasma triglycerides. The concentration of $18: 2$ in the unesterified fatty acids reached a peak $3 \mathrm{~h}$ after the start of infusion, $\mathrm{I} h$ earlier than the first peak concentration of $18: 3$, and then decreased sharply during the following $3 \mathrm{~h}$. Moreover, in spite of the high ratio of $18: 3$ to $18: 2$ in the linseed oil the concentration of $18: 2$ was higher than the concentration of $18: 3$ in the plasma unesterified fatty acids $3 \mathrm{~h}$ after infusion began. This was the reverse of the situation observed in the plasma triglycerides. During the

Table 3. Effect of the infusion of an emulsion of linseed oil into the abomasum of a sheep on the fatty acid composition (major components, weight percentages of the total) of the plasma cholesteryl esters and phospholipids

\begin{tabular}{|c|c|c|c|c|c|c|c|c|c|c|c|c|c|c|c|}
\hline \multirow{3}{*}{$\begin{array}{l}\text { Time after } \\
\text { beginning of } \\
\text { infusion } \\
\text { (h) }\end{array}$} & \multirow{2}{*}{\multicolumn{7}{|c|}{ Cholesteryl esters }} & \multicolumn{8}{|c|}{ Phospholipids } \\
\hline & & & & & & & & & & & & & & & 22 \\
\hline & I6:0 & I6: I & 18:0 & I8: I & $18: 2$ & I $8: 3$ & $0: 4$ & 16:0 & I $6: 1$ & $18: 0$ & $18: I$ & $18: 2$ & $18: 3$ & $20: 4$ & $22: 6$ \\
\hline o & $15 \cdot 3$ & $2 \cdot 8$ & $5 \cdot 5$ & $36 \cdot 5$ & 24.9 & $3 \cdot 7$ & $2 \cdot 0$ & $2 I \cdot 4$ & $2 \cdot 0$ & $28 \cdot 0$ & $24 \cdot 3$ & 10.8 & $x \cdot 3$ & 6.7 & 3.4 \\
\hline 0.5 & $19^{\circ} \mathrm{I}$ & $2 \cdot 4$ & $5 \cdot 3$ & $37 \cdot 4$ & $21 \cdot 5$ & $3 \cdot 5$ & I 8 & I9.6 & $x \cdot 0$ & 27.7 & 23.4 & 10.7 & $I \cdot 3$ & $7 \cdot 8$ & 5.9 \\
\hline 1.0 & $17 \cdot 5$ & $2 \cdot 5$ & $5 \cdot 5$ & 37.8 & $23 \cdot 6$ & 3.7 & $2 \cdot 8$ & $21 \cdot 9$ & $2 \cdot 4$ & $27^{\prime} I$ & 23.7 & $10 \cdot 8$ & $1 \cdot 2$ & $7 \cdot 1$ & $5 \cdot 3$ \\
\hline$x \cdot 5$ & I 4.8 & $2 \cdot 2$ & 4.0 & 40.9 & 24.9 & $3 \cdot 4$ & $2 \cdot 5$ & $24 \cdot 3$ & $I \cdot 2$ & $25 \cdot 6$ & $25 \cdot 6$ & II $\cdot 0$ & $1 \cdot 4$ & $5 \cdot 8$ & $3 \cdot 8$ \\
\hline $2 \cdot 0$ & 14.8 & $2 \cdot 5$ & $4 \cdot I$ & 37.9 & $23 \cdot 6$ & $3 \cdot 7$ & $2 \cdot 9$ & $22 \cdot 1$ & $1 \cdot 3$ & 25.8 & $23 \cdot 4$ & $\mathrm{r} 33$ & $2 \cdot 4$ & 6.2 & 3.6 \\
\hline $3 \cdot 0$ & $14^{*} 4$ & 3.0 & $4 \cdot 4$ & $37 \cdot 2$ & 24.9 & $4^{\circ} 9$ & $2 \cdot 3$ & $22 \cdot 5$ & $1 \cdot 2$ & 26.9 & 224 & 10.9 & I. 8 & $7 \cdot 3$ & 40 \\
\hline 40 & $\times 2.9$ & $3 \cdot 1$ & $6 \cdot 5$ & 35.4 & $25 \cdot 3$ & $3 \cdot 8$ & $3 \cdot 2$ & 20.0 & $1 \cdot 7$ & $26 \cdot 2$ & $24 \cdot 1$ & I I 9 & $2 \cdot I$ & $7 \cdot 1$ & $4 \cdot 8$ \\
\hline 6.0 & 13.9 & $2 \cdot 3$ & $5 \cdot 3$ & 40.9 & 24.0 & $3 \cdot 7$ & $4 \cdot 4$ & I 8.5 & $1 \cdot 3$ & $29 \cdot 4$ & $22 \cdot 6$ & $14 \cdot 2$ & $2 \cdot 6$ & $6 \cdot 2$ & 4.0 \\
\hline 8.0 & 16.7 & $2 \cdot 1$ & $4 \cdot 2$ & $3^{8 \cdot I}$ & 23.9 & 4.2 & $3 \cdot 4$ & $2 I \cdot 2$ & $1 \cdot 2$ & $32 \cdot 7$ & $22 \cdot 4$ & 9.0 & $2 \cdot 4$ & $5 \cdot 2$ & $4 \cdot 3$ \\
\hline 10.0 & I $6 \cdot I$ & $2 \cdot 5$ & 3.7 & $4 I \cdot 2$ & $26 \cdot 1$ & $4 \cdot 3$ & 24 & 20.0 & $1 \cdot 5$ & 29.5 & $2 \mathrm{I} \cdot 8$ & 114 & 3.9 & $6 \cdot 6$ & $4 \cdot 3$ \\
\hline 24.0 & I $2 \cdot 3$ & $I \cdot 4$ & $3^{\cdot I}$ & 44.0 & $26 \cdot 4$ & $6 \cdot 6$ & 32 & 20.5 & 1.4 & $29 \cdot 2$ & $22 \cdot 0$ & 13.0 & 5.5 & 47 & $3 \cdot 3$ \\
\hline
\end{tabular}

first $2 \mathrm{~h}$ the concentration of $\mathrm{r} 8: \mathrm{I}$ in the unesterified fatty acids tended to decrease but it remained relatively unchanged between 3 and io $h$ after infusion began. After $24 \mathrm{~h}$ the concentration of $\mathrm{I} 8: \mathrm{I}$ in the plasma unesterified fatty acids had returned to the value observed in the pre-infusion plasma sample. Throughout the experiment, the concentration of $16: 0$ and $18: 0$ in the plasma unesterified fatty acids varied independently (cf. the plasma triglycerides) and somewhat inconsistently, but between 3 and $24 \mathrm{~h}$ after infusion began, the concentration of $16: 0$ tended to vary inversely with the concentration of $18: 3$.

The fatty acid composition of the cholesteryl esters and phospholipids in the plasma before and at various times after the start of the intra-abomasal infusion of linseed oil are given in Table 3. The fatty acid composition of these major plasma lipid fractions did not change appreciably during the experiment. In particular, there was no evidence of extensive incorporation of $18: 3$ or $18: 2$ into the plasma cholesteryl esters and phospholipids, as was observed in the plasma triglycerides and unesterified fatty acids. However, the small increases in the concentration of $18: 3$ in the cholesteryl esters and phospholipids between ro and $24 \mathrm{~h}$ after infusion began could be seen.

Expt 2. As in Expt I, thin-layer chromatograms of the plasma lipids indicated that the proportion of triglycerides in the total lipid was increased during the to $h$ after the intra-abomasal infusion of the triglyceride emulsion began. 
The fatty acid compositions of the plasma triglycerides and unesterified fatty acids in the samples of blood taken before and at various times after the start of the infusion of maize oil into the abomasum of sheep no. 2 are given in Table 4 . Throughout the experiment, these two lipid fractions contained only trace concentrations of $18: 3$. The concentration of $\mathrm{I} 8: 2$ in the plasma triglycerides began to rise $\mathrm{I} h$ after infusion began and it reached a single concentration peak at $6 \mathrm{~h}$. Even after $24 \mathrm{~h}$ the concentration of $18: 2$ in the plasma triglycerides of sheep no. 2 was still considerably greater than the value observed before infusion began. As in Expt 1 , the concentration of $18: \mathrm{I}$ in the plasma triglycerides was not altered appreciably by the infusion of the triglyceride emulsion. In the plasma unesterified fatty acids the changes in the concentration of $18: 2$ with time were similar to the changes in the concentration of

Table 4. Effect of the infusion of an emulsion of maize oil into the abomasum of a sheep on the fatty acid composition (major components, weight percentages of the total) of the plasma triglycerides and unesterified fatty acids

\begin{tabular}{|c|c|c|c|c|c|c|c|c|c|c|}
\hline \multirow{2}{*}{$\begin{array}{l}\text { Time after } \\
\text { beginning of } \\
\text { infusion }(h)\end{array}$} & \multicolumn{5}{|c|}{ Triglycerides } & \multicolumn{5}{|c|}{ Unesterified fatty acids } \\
\hline & I6:0 & $16: 1$ & I8:0 & $18: 1$ & $18: 2$ & $16: 0$ & $16: 1$ & $18: 0$ & I8: I & $18: 2$ \\
\hline 0 & $3 r \cdot 9$ & $2 \cdot 8$ & 24.9 & 33.9 & $3 \cdot I$ & $24 \cdot 9$ & $3 \cdot 3$ & $22 \cdot 9$ & 44.4 & $2 \cdot 0$ \\
\hline 0.5 & $34^{\circ} 7$ & $3 \cdot 4$ & $27 \cdot 3$ & $28 \cdot 3$ & 3.5 & & & No samp & & \\
\hline$x \cdot 0$ & $35 \cdot 4$ & $2 \cdot 8$ & $23 \cdot 7$ & $29 \cdot 3$ & $5 \cdot 6$ & 20.9 & $2 \cdot 1$ & $33 \cdot 0$ & $39 \cdot 3$ & $2 \cdot 6$ \\
\hline I 5 & 33.0 & $3 \cdot 5$ & $2 I \cdot 9$ & 30.8 & $9 \cdot I$ & $22 \cdot I$ & $5 \cdot 9$ & $36 \cdot 3$ & 30.0 & $2 \cdot 5$ \\
\hline $2 \cdot 0$ & $26 \cdot 2$ & $2 \cdot 6$ & 15.0 & $32 \cdot 3$ & $21 \cdot 0$ & $2 I \cdot 4$ & 3.8 & $34 \circ$ & $33^{\cdot} \cdot$ & $5 \cdot 2$ \\
\hline $3^{\circ} 0$ & $22 \cdot 9$ & $I \cdot 6$ & I $3 \cdot 3$ & $28 \cdot 7$ & $29 \cdot 4$ & $20 \cdot 5$ & $3 \cdot x$ & $28 \cdot I$ & $33 \cdot 2$ & 13.9 \\
\hline $4 \cdot 0$ & I8.4 & $\mathbf{I} \cdot 9$ & $8 \cdot 4$ & $29^{\circ} 0$ & $38 \cdot 8$ & $20 \cdot 2$ & $2 \cdot 7$ & 25.4 & $34 \cdot 8$ & $15 \cdot 0$ \\
\hline $6 \cdot 0$ & I 5.8 & $I \cdot 9$ & $7 \cdot 3$ & 30.5 & $41 \cdot 4$ & $19 \cdot 6$ & $3 \cdot 7$ & $22 \cdot 6$ & $3 I \cdot 6$ & 20.1 \\
\hline 8.0 & $2 \mathrm{I} \cdot 3$ & $2 \cdot 2$ & $9 \cdot 9$ & 30.0 & 34.8 & & & No samp & & \\
\hline 10.0 & 20.1 & $\mathrm{I} \cdot 9$ & 10.4 & $28 \cdot 9$ & 34.4 & & & No samp & & \\
\hline $24 \cdot 0$ & 29.9 & $2 \cdot 3$ & $19 \cdot 8$ & $28 \cdot 7$ & 14.0 & $27 \cdot 4$ & $3 \cdot 0$ & 18.9 & $46 \cdot 7$ & $1 \cdot 8$ \\
\hline
\end{tabular}

I $8: 2$ in the plasma triglycerides, but the maximum concentration of $18: 2$ found was only about half of the maximum concentration of $18: 2$ in the plasma triglycerides. The concentration of $18: \mathrm{I}$ in the unesterified fatty acids decreased during the first I. $5 \mathrm{~h}$, but remained relatively unchanged over the next $4.5 \mathrm{~h}$; after $24 \mathrm{~h}$ the concentration of $\mathrm{r}$ 8: $\mathrm{r}$ had returned to the value observed before infusion began (cf. Expt $\mathrm{r}$ ). Changes in the concentration of $16: 0$ in the plasma unesterified fatty acids were broadly similar to the changes observed for $\mathrm{I} 8: \mathrm{I}$, but the concentration of $\mathrm{I} 8: 0$ increased to a maximum at $2 \mathrm{~h}$ and then decreased gradually over the next $4 \mathrm{~h}$ to the value observed in the pre-infusion sample of plasma.

The fatty acid composition of the plasma cholesteryl esters and phospholipids before and at various times after the start of infusion are given in Table 5 . There were no pronounced changes in the fatty acid composition of the plasma cholesteryl esters during the experiment, but the increase in the concentration of $18: 2$ and the decrease in the concentration of 16 : 0 between the Ioth and 24 th hour should be noted (cf. Expt I). There was a marked increase in the concentration of $18: 2$ in

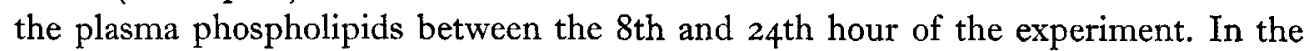
plasma phospholipids there were no marked changes in the concentrations of $16: 0$ 
and $18: 0$, but the concentrations of $18: 1$ and $18: 3$ tended to decrease towards the end of the experiment.

Expt 3. The fatty acid compositions of the plasma triglycerides and unesterified fatty acids in the samples of blood taken before and at various times after the start of the infusion of linoleic acid into the abomasum of sheep no. 3 are given in Table 6. The concentration of $18: 2$ in the plasma triglycerides increased to a first concentration peak $7 \mathrm{~h}$ after infusion began. Between 7 and $13 \mathrm{~h}$ the concentration of $18: 2$ in the

Table 5. Effect of the infusion of an emulsion of maize oil into the abomasum of a sheep on the fatty acid composition (major components, weight percentages of the total) of the plasma cholesteryl esters and phospholipids

\begin{tabular}{|c|c|c|c|c|c|c|c|c|c|c|c|c|c|c|c|}
\hline \multirow{3}{*}{$\begin{array}{l}\text { Time after } \\
\text { beginning of } \\
\text { infusion } \\
\text { (h) }\end{array}$} & \multirow{2}{*}{\multicolumn{7}{|c|}{ Cholesteryl esters }} & \multicolumn{8}{|c|}{ Phospholipids } \\
\hline & & & & & & & & & & & & & & & \\
\hline & $x 6: 0$ & $16: 1$ & 18:0 & I $8:$ I & $18: 2$ & $18: 3$ & $0: 4$ & $16: 0$ & $16: 1$ & r8:0 & 18: I & $18: 2$ & $18: 3$ & . & \\
\hline 0 & I 3.9 & $2 \cdot 3$ & $3 \cdot 6$ & $4 I \cdot 8$ & $24 \cdot 3$ & $5 \cdot 2$ & $3 \cdot 5$ & 19.9 & $I \cdot 3$ & $24 \cdot 3$ & $27 \cdot 5$ & I 3.8 & $2 \cdot I$ & $6 \cdot I$ & $3 \cdot 6$ \\
\hline 0.5 & 142 & $2 \cdot 6$ & $3 \cdot 6$ & $42 \cdot I$ & 25.0 & $5 \cdot 3$ & 3.6 & $19 \cdot 2$ & $I \cdot 2$ & $27 \cdot 2$ & $27 \cdot 0$ & I $2 \cdot 9$ & $2 \cdot 7$ & $7 \cdot 6$ & $3 \cdot 6$ \\
\hline 1.0 & $16 \cdot 6$ & $1 \cdot 7$ & 5.0 & $4 I \times I$ & $25 \cdot 2$ & 5.0 & $2 \cdot 6$ & 19.7 & $I \cdot I$ & $27 \cdot 6$ & 27.4 & $x+\cdot 6$ & $1 \cdot 8$ & $5 \cdot 5$ & $3 \cdot 2$ \\
\hline $1 \cdot 5$ & 14.3 & $3 \cdot 2$ & $3 \cdot 3$ & $42 \cdot 0$ & 24.9 & $5 \cdot \mathrm{I}$ & 3.0 & 19.9 & $2 \cdot 0$ & $26 \cdot 6$ & 29.9 & $17 \cdot 1$ & $3 \cdot 3$ & 6.9 & $4 \cdot 8$ \\
\hline $2 \cdot 0$ & 14.3 & 3.0 & 3.0 & $42 \cdot 9$ & $25 \cdot 0$ & 5.6 & 2.9 & 19.8 & $I \cdot O$ & 25.8 & $26 \cdot I$ & 14.5 & 3.7 & $7 \cdot 9$ & 3.5 \\
\hline 3.0 & $12 \cdot 0$ & 3.9 & 3.0 & $47^{\circ} \circ$ & 24.9 & $4 \cdot 3$ & $2 \cdot 7$ & $18 \cdot 0$ & $2 \cdot 9$ & 23.2 & 27.0 & 14.3 & $2 \cdot 9$ & $6 \cdot 3$ & $3 \cdot 5$ \\
\hline 4.0 & 14.6 & $2 \cdot 8$ & 3.5 & $43 \cdot 3$ & 25.8 & 49 & $3 \cdot I$ & I 9.2 & $I \cdot I$ & 24.4 & $26 \cdot 4$ & $15 \cdot x$ & $2 \cdot I$ & $6 \cdot 5$ & $3 \cdot 6$ \\
\hline 60 & I 5.0 & $3 \cdot 4$ & $3^{-I}$ & $43 \cdot 1$ & 25.7 & 4.9 & $2 \cdot 9$ & I 9.2 & $I \cdot 4$ & 24.1 & $26 \cdot \mathrm{I}$ & 16.6 & $1 \cdot 7$ & 5.8 & $3 \cdot 8$ \\
\hline $8 \cdot 0$ & I 5.5 & $2 \cdot 6$ & $4^{\cdot I}$ & $42 \cdot 4$ & $24 \circ$ & 5.9 & $3 \cdot 4$ & $20 \cdot 5$ & $I \cdot 4$ & $25^{\circ}$ & 25.0 & 16.6 & $1 \cdot 6$ & 5.5 & 37 \\
\hline 10.0 & I 8.4 & 3.0 & $2 \cdot 8$ & 40.2 & 25.8 & 4.9 & $1 \cdot 5$ & $18 \cdot 5$ & $I \cdot 2$ & 22.7 & 23.6 & 22.7 & I. 5 & 54 & $3 \cdot 3$ \\
\hline 240 & I 3.6 & 2.0 & $2 \cdot 8$ & 40.8 & $31 \cdot 0$ & $4 \cdot 3$ & $2 \cdot 3$ & 16.7 & $1 \cdot 3$ & $24 \cdot 3$ & I 9.7 & 25.4 & 0.8 & 5.8 & 4.0 \\
\hline
\end{tabular}

Table 6. Effect of the infusion of an emulsion of linoleic acid into the abomasum of a sheep on the fatty acid compositions (major components, weight percentages of the total) of the plasma triglycerides and unesterified fatty acids

\begin{tabular}{|c|c|c|c|c|c|c|c|c|}
\hline \multirow{2}{*}{$\begin{array}{l}\quad \text { Time } \\
\text { after beginning } \\
\text { of infusion }(\mathrm{h})\end{array}$} & \multicolumn{4}{|c|}{ Triglycerides } & \multicolumn{4}{|c|}{ Unesterified fatty acids } \\
\hline & I 6:0 & I8:0 & I $8: 1$ & I $8: 2$ & $16: 0$ & I 8:0 & I $8: 1$ & I $8: 2$ \\
\hline 0 & $29 \cdot 2$ & $22 \cdot 9$ & $24 \div 3$ & 4.4 & $25 \cdot 3$ & $37 \cdot 4$ & $23 \cdot 4$ & $2 \cdot 0$ \\
\hline 0.5 & $28 \cdot 3$ & 23.9 & $24 \cdot 2$ & $5 \cdot \mathrm{I}$ & $24^{\cdot I}$ & $36 \cdot 0$ & $24 \cdot 4$ & $2 \cdot 7$ \\
\hline $1 \cdot 0$ & $26 \cdot 4$ & $24 \cdot I$ & $26 \cdot I$ & $7 \cdot 4$ & $26 \cdot 4$ & $37 \cdot 0$ & $20 \cdot 3$ & $\mathbf{I} \cdot 8$ \\
\hline $1 \cdot 5$ & $24 \cdot 9$ & $17 \cdot 2$ & $24 \cdot 0$ & $17 \cdot 8$ & $26 \cdot 3$ & $35 \cdot 0$ & $25 \cdot 3$ & 4.0 \\
\hline $2 \cdot 0$ & $22 \cdot 5$ & $14 \cdot 1$ & $23 \cdot 3$ & $26 \cdot 7$ & $21 \cdot 4$ & $36 \cdot 2$ & $30 \cdot \mathrm{I}$ & $6 \cdot 9$ \\
\hline $3 \cdot 0$ & 19.5 & $9 \cdot 6$ & $2 I \cdot 0$ & $29 \cdot 1$ & $2 I \cdot 3$ & $32 \cdot 2$ & $30 \cdot 8$ & $8 \cdot 3$ \\
\hline $5 \cdot 0$ & 19.8 & II'O & 24.9 & $30 \cdot 1$ & $2 I \cdot 3$ & 24.7 & $35 \cdot 6$ & I0.9 \\
\hline $7 \cdot 0$ & 19.0 & $9 \cdot 3$ & $26 \cdot 5$ & $31 \cdot 8$ & $21 \cdot 0$ & $21 \cdot 7$ & $3^{6 \cdot 5}$ & $13 \cdot 7$ \\
\hline 9.0 & $2 x \cdot 3$ & I I 4 & $26 \cdot 8$ & $27 \cdot I$ & $22 \cdot I$ & $27 \cdot 9$ & $34 \cdot 2$ & $8 \cdot 7$ \\
\hline II O & 25.6 & I 2.8 & $26 \cdot 4$ & 24.6 & $23 \cdot 4$ & 30.9 & $32 \cdot 6$ & 5.0 \\
\hline 13.0 & $27 \cdot 5$ & I 5.4 & $23 \cdot 2$ & $22 \cdot 3$ & 27.8 & $35^{\circ} \circ$ & $20 \cdot 7$ & 4.5 \\
\hline $15^{\circ} \mathrm{O}$ & 19.8 & $9 \cdot 6$ & $23 \cdot 2$ & 35.8 & $22 \cdot I$ & 30.1 & $26 \cdot I$ & I 2.8 \\
\hline 17.0 & $20 \cdot 3$ & 10.2 & 25.0 & 37.4 & $26 \cdot I$ & $3 I \cdot 0$ & $26 \cdot 8$ & 8.0 \\
\hline $21 \cdot 0$ & $21 \cdot 5$ & I I 4 & $22 \cdot 4$ & 38.0 & $27 \cdot 4$ & 29.5 & 28.0 & 5.0 \\
\hline $25^{\circ} 0$ & I8.8 & 7.9 & 23.7 & $42 \cdot 2$ & $24^{\circ} I$ & $27 \cdot 4$ & $32 \cdot 6$ & $9 \cdot 3$ \\
\hline 29.0 & $20 \cdot 2$ & 10.5 & 23.0 & 38.4 & $26 \cdot 5$ & $22 \cdot 3$ & $26 \cdot 2$ & 14.5 \\
\hline $33^{\circ} \mathrm{O}$ & $2 \mathrm{r} \cdot 8$ & I $2 \cdot 3$ & $2 I \cdot I$ & $35 \cdot 7$ & 23.7 & $22 \cdot 8$ & 20.9 & $18 \cdot 4$ \\
\hline $39^{\circ} \circ$ & 24.0 & 18.6 & $22 \cdot 1$ & $22 \cdot 5$ & $25 \cdot 3$ & $29^{\circ} 1$ & $25^{\prime 2}$ & $5 \cdot 9$ \\
\hline $45^{\circ} \mathrm{O}$ & $25^{\circ}$ & I9.5 & $22 \cdot 6$ & 16.5 & 24.8 & $3 I \cdot 8$ & $3 I \cdot I$ & 37 \\
\hline $5 \mathrm{I} \cdot 0$ & $26 \cdot 5$ & $22 \cdot 2$ & 23.7 & 10.1 & $23 \cdot I$ & $32 \cdot 0$ & $3 I \cdot 4$ & $3 \cdot 8$ \\
\hline
\end{tabular}


plasma triglycerides decreased but, after $\mathrm{I} 3 \mathrm{~h}$ it increased again to reach a second concentration peak $25 \mathrm{~h}$ after infusion began. It should be noted that on the ist day of the experiment, sheep no. 3 was given the second half of its daily ration of hay at $10.00 \mathrm{~h}$ (i.e. $\mathrm{I} 3 \mathrm{~h}$ after infusion began). Between 25 and $5 \mathrm{I} \mathrm{h}$ the concentration of I 8:2 decreased markedly but the plasma triglycerides at $5^{\mathrm{I}} \mathrm{h}$ still contained higher concentrations of $18: 2$ than did the plasma triglycerides before infusion began. As in Expts $I$ and 2, the concentration of $I 8: I$ in the plasma triglycerides did not change appreciably during the experiment. The changes in the composition of the plasma unesterified fatty acids during the experiment present a somewhat complicated

Table 7. Effect of an infusion of an emulsion of linoleic acid into the abomasum of a sheep on the fatty acid compositions (major components, weight percentages of the total) of the plasma cholesteryl esters and phospholipids

\begin{tabular}{|c|c|c|c|c|c|c|c|c|}
\hline \multirow{2}{*}{$\begin{array}{l}\text { Time } \\
\text { after beginning } \\
\text { of infusion }(h)\end{array}$} & \multicolumn{4}{|c|}{ Cholesteryl esters } & \multicolumn{4}{|c|}{ Phospholipids } \\
\hline & $16: 0$ & I8:0 & I8: I & $18: 2$ & I6:0 & 18:0 & 18:1 & I $8: 2$ \\
\hline$\circ$ & $14 \cdot 6$ & $3 \cdot 9$ & $35 \cdot 8$ & 29.9 & 13.4 & I9. I & $19 \cdot I$ & $19^{\cdot} \mathrm{I}$ \\
\hline 0.5 & $12 \cdot 7$ & $3 \cdot 4$ & $34 \cdot 9$ & $29 \cdot 9$ & 14.0 & $\mathrm{I} 8 \cdot \mathrm{I}$ & I $8 \cdot 3$ & $20 \cdot 0$ \\
\hline$I \cdot O$ & 13.5 & $4 \cdot 3$ & $32 \cdot 4$ & 28.7 & I $3 \cdot 6$ & $18 \cdot 2$ & 18.6 & $20 \cdot 4$ \\
\hline$I \cdot 5$ & $12 \cdot 2$ & $3 \cdot 2$ & $37 \cdot 2$ & 30.4 & $13 \cdot 6$ & $20 \cdot 2$ & 18.7 & 19.6 \\
\hline $2 \cdot 0$ & $12 \cdot 2$ & $2 \cdot 8$ & $37 \cdot 1$ & $30 \cdot 5$ & 14.9 & $2 \times \cdot 5$ & 19.5 & 19.5 \\
\hline 3.0 & I3. I & $2 \cdot 4$ & 35.4 & $30 \cdot 6$ & I5.8 & $20 \cdot 3$ & $21 \cdot 5$ & $20 \cdot 8$ \\
\hline $5^{\circ} \mathrm{O}$ & $12 \cdot 7$ & $3 \cdot 4$ & $36 \cdot 2$ & 30.9 & $15 \cdot 5$ & $20 \cdot 2$ & $22 \cdot 6$ & $2 I \cdot 2$ \\
\hline $7^{\circ} 0$ & 13.9 & $3 \cdot 2$ & $35 \cdot 2$ & $29 \cdot 2$ & $15 \cdot 5$ & $20 \cdot 2$ & $22 \cdot 4$ & $20 \cdot 6$ \\
\hline 9.0 & $12 \cdot 7$ & $2 \cdot 6$ & $36 \cdot 6$ & $31 \cdot 0$ & $14^{\cdot 6}$ & $22 \cdot 9$ & $22 \cdot 8$ & 20.5 \\
\hline II $\cdot 0$ & 14.0 & $3 \cdot 4$ & $35 \cdot 7$ & $28 \cdot 8$ & $14 \%$ & $2 I^{*} 9$ & 18.4 & 24.0 \\
\hline I 3.0 & 14.3 & $3 \cdot 5$ & 35.7 & 28.6 & 14.2 & $20 \cdot 9$ & $17^{\prime} I$ & $25 \cdot 2$ \\
\hline 15.0 & 12.9 & 3.0 & $34^{\circ} \mathrm{I}$ & $30 \cdot 7$ & 14.5 & $20 \cdot 5$ & 17.8 & $25 \circ$ \\
\hline $17 \cdot 0$ & 13.8 & $3 \cdot 3$ & 33.4 & 29.0 & × 3.6 & 20.8 & 15.8 & 26.6 \\
\hline $21 \cdot 0$ & $14 \cdot 2$ & 4.7 & 35.7 & $29 \cdot 3$ & $14^{\circ} 9$ & $20 \cdot I$ & 15.0 & $27 \cdot 4$ \\
\hline $25^{\circ} 0$ & 14.8 & $3 \cdot 6$ & $38 \cdot 5$ & 27.8 & 14.2 & 20.8 & 154 & 27.0 \\
\hline 29.0 & 13.9 & 4.0 & $33 \cdot 6$ & 32.0 & $I 4 \cdot I$ & $2 r \cdot 4$ & 14.9 & $27 \cdot 6$ \\
\hline 33.0 & $12 \cdot 3$ & $2 \cdot 3$ & $33^{\prime} I$ & $3^{6 \cdot 6}$ & 14.5 & $21 \cdot 5$ & 14.4 & $28 \cdot I$ \\
\hline $39^{\circ} 0$ & $12 \cdot 1$ & $4 . I$ & $31 \cdot 4$ & $3^{8 \cdot 6}$ & $13 \cdot 3$ & $20 \cdot 2$ & 14.0 & $28 \cdot 3$ \\
\hline 45.0 & II $\cdot 3$ & $2 \cdot 6$ & 30.8 & $40 \cdot 1$ & 13.8 & $19^{\circ} \mathrm{I}$ & 13.2 & $29 \cdot 5$ \\
\hline $5 \mathrm{I} \cdot 0$ & $r_{3 \cdot 2}$ & $2 \cdot 7$ & $27 \cdot 4$ & $42 \cdot 4$ & 14.0 & 19.4 & 12.6 & $29 \cdot 7$ \\
\hline
\end{tabular}

pattern. Unlike the plasma triglycerides, there were three distinct peak concentrations of $18: 2$ in the unesterified fatty acids. The first of these coincided with the first peak concentration of linoleic acid in the plasma triglycerides (at $7 \mathrm{~h}$ ). The second fairly sharp peak occurred is $h$ after infusion began ( $3 \mathrm{~h}$ after the sheep had been given the second portion of its ration of hay on the ist day of the experiment). The sheep received its next meal $23 \mathrm{~h}$ after infusion began and the concentration of $18: 2$ in the plasma unesterified fatty acids began to rise again and reached the third concentration peak at $33 \mathrm{~h}$. During the first $\mathrm{I} 3 \mathrm{~h}$ of the experiment, changes in the concentration of $\mathrm{I} 8: \mathrm{I}$ in the unesterified fatty acids were similar to those observed for $18: 2$, but after $2 \mathrm{I} h$ the concentration of $\mathrm{I} 8: \mathrm{I}$ appeared to vary inversely with the concentration of $18: 2$. In the unesterified fatty acids there was a tendency for the concentration of $18: 0$ to vary inversely with the concentration of $18: 2$.

The fatty acid compositions of the plasma cholesteryl esters and phospholipids 
in the samples of blood taken before and at various times after the start of the infusion of linoleic acid into the abomasum of sheep no. 3 are given in Table 7 . The fatty acid composition of the cholesteryl esters remained relatively unchanged for the first $25 \mathrm{~h}$ of the experiment, but between 25 and $5 \mathrm{I} \mathrm{h}$ the concentration of $18: 2$ gradually increased and the concentration of 18 : I decreased. Similar changes in the concentration of $18: 2$ and $18: \mathrm{I}$ were observed in the plasma phospholipids, but these changes began to occur considerably earlier (after only $9 \mathrm{~h}$ ) than they did in the plasma cholesteryl esters.

In all three experiments, the concentrations of $16: 0$ and $18: 0$ in the plasma triglycerides changed in parallel and the changes in the concentrations of these two saturated fatty acids were the reverse of the changes observed for the concentrations of $18: 3$ (Expt I) or $18: 2$ (Expts 2 and 3 ) in the plasma triglycerides. In Expt I there were highly significant negative correlations between the concentrations of $18: 3$ and $18: 0(r=-0.988)$ and between the concentrations of $18: 3$ and $x 6: 0(r=-0.968)$ in the plasma triglycerides throughout the $24 \mathrm{~h}$ of the experiment. In Expts 2 and 3 there were highly significant negative correlations between the concentrations of $18: 2$ and $18: 0(r=-0.991$ and -0.945 for Expts 2 and 3 respectively) and between the concentrations of $18: 2$ and $16: 0(r=-0.984$ and -0.866 for Expts 2 and 3 respectively).

\section{DISCUSSION}

The results of Expts 1 and 2 clearly show that the infusion of single doses of linseed oil or maize oil into the abomasum of sheep resulted in a fairly rapid incorporation of $18: 3$ or $18: 2$ into the plasma triglycerides. The concentration of $18: 3$ (Expt $\mathrm{I}$ ) and $18: 2$ (Expt 2) in the plasma triglycerides began to increase $\mathrm{I} \cdot 5 \mathrm{~h}$ after infusion of the triglyceride emulsion had begun. Thus, there is no reason to suppose that, under the conditions of Expts $I$ and 2, the mechanisms of digestion and absorption of the infused triglyceride were any different from the mechanisms that obtain in monogastric animals (Senior, 1964). Presumably, the emulsion passed from the abomasum into the small intestine where the triglyceride was partially hydrolysed by pancreatic lipase (Heath \& Morris, r963). The resulting $\beta$-monoglycerides and fatty acids together with bile acids would then form soluble micelles from which the monoglycerides and fatty acids would be taken up by the cells of the intestinal mucosa. The monoglycerides and fatty acids would then be utilized for the re-synthesis of triglycerides which would pass into the intestinal and thoracic lymph ducts and hence into the blood. However, under normal feeding conditions, it is doubtful whether glycerides as such ever reach the small intestine of ruminants. Dietary glycerides are effectively hydrolysed to fatty acids and glycerol by rumen micro-organisms (Garton, Lough \& Vioque, I96r). Thus, the small intestine of the ruminant normally receives unesterified fatty acids, but no partial glycerides. Expt 3 was undertaken to determine whether the infusion into the abomasum of unesterified 18:2 influenced the pattern of incorporation of this fatty acid into the various plasma lipid fractions. The results given in Tables 4 and 6 show that the pattern of incorporation into the blood triglycerides was very similar irrespective of whether the 
18:2 was infused into the abomasum of the sheep as triglyceride or free acid. The precise mechanism of micelle formation in the small intestine of ruminants under normal dietary conditions is not known, but Garton (1965) has suggested that, in the ruminant small intestine, lysophosphatidyl choline may have the same function with respect to micelle formation as do $\beta$-mono-glycerides in the small intestine of monogastric animals.

The rate of passage of the infused emulsion from the abomasum into the small intestine will undoubtedly be an important factor in determining the rate of incorporation of $18: 3$ or $18: 2$ into the blood triglycerides, and it is reasonable to assume that there was a relatively high rate of passage into the small intestine immediately after the emulsion had been infused into the abomasum. In Expt 2, in which food was withheld from the sheep until the last blood sample was taken, there was only one concentration peak of $18: 2$ in the plasma triglycerides. In Expts I and 3 the sheep were given meals of hay 7 and $13 \mathrm{~h}$, respectively, after infusion began and these additional meals resulted in the appearance of secondary concentration peaks of 18:3 or $18: 2$ in the plasma triglycerides. Thus, the ingestion of food appeared to initiate an increased rate of passage of digesta including the infused emulsion from the abomasum into the small intestine. It is perhaps worth recording that in similar infusion experiments (unpublished) we have noticed that secondary concentration peaks of $18: 3$ or $18: 2$ also occurred in the plasma triglycerides of sheep from which food was withheld. However, in these instances, the appearance of secondary concentration peaks of $18: 3$ or $18: 2$ in the plasma triglycerides of the experimental sheep was always related to the time that other sheep, housed in the same metabolism room, were given food. This suggests that the stimulus resulting from the rattling of nearby food containers, etc., is sufficient to result in an increased rate of flow of digesta from the abomasum into the small intestine. It should be noted that sheep no. 2 was housed by itself in a room that contained no other experimental animals.

At present, no explanation can be put forward to account for the striking interrelationships that were observed between the concentrations of $16: 0,18: 0$ and $18: 3$ or $18: 2$ in the plasma triglycerides of the sheep in all these experiments. Determination of the distribution of the various fatty acids between the I-, 2- and 3-positions of the plasma triglycerides might explain why the concentrations of $18: 3$ or I8:2 varied inversely with the concentrations of the two saturated fatty acids whilst the concentration of $18: 1$ remained relatively unchanged.

In view of the results of the previous experiment (Moore et al. 1968), it was surprising to find that $18: 3$ and $18: 2$ were not more rapidly incorporated into the plasma cholesteryl esters and phospholipids. In the first two experiments, the concentrations of $18: 3$ (Expt 1 ) and $18: 2$ (Expt 2) in the plasma cholesteryl esters did not appear to increase until sometime between Io and $24 \mathrm{~h}$. That these increases occurred nearer $24 \mathrm{~h}$ may be inferred from the results of Expt 3 , in which it was found that the concentration of $18: 2$ in the plasma cholesteryl esters did not increase appreciably until after $25 \mathrm{~h}$. These findings lend no support to the suggestion of Duncan \& Garton (1962) that in ruminants the $\mathrm{C}_{18}$ polyunsaturated fatty acids that escape hydrogenation in the rumen are preferentially esterified with cholesterol at 
the site of absorption in the small intestine. In the first two experiments, the concentrations of $18: 3$ (Expt I) and $18: 2$ (Expt 2) in the plasma phospholipids began to increase after $8 \mathrm{~h}$ whereas in Expt 3 the concentration of $18: 2$ in this fraction began to increase progressively after $9 \mathrm{~h}$. Thus, it would seem that the incorporation of $18: 2$ into the different plasma lipid fractions followed a definite pattern: incorporation into the triglyceride fraction began after about $\mathrm{I} \cdot 5 \mathrm{~h}$, whereas incorporation into the phospholipid and cholesteryl ester fractions did not begin until after $8-9 \mathrm{~h}$ and $24^{-25} \mathrm{~h}$ respectively. Such a sequence of events suggests that, after absorption from the small intestine, $18: 2$ is transported in triglyceride form to the liver where the triglycerides are partially or completely hydrolysed. The specificity of the enzyme systems in the liver would appear to be such that the liberated I8:2 is not utilized to any great extent for the re-synthesis of triglycerides, but it is utilized extensively for the synthesis of phospholipids and then for the synthesis of cholesteryl esters. Interpretation of the changes in the composition of the plasma unesterified fatty acids is complicated by the fact that this fraction will tend to be in equilibrium with the various forms of esterified fatty acids in the plasma and tissues.

The present results are not consistent with the findings of the previous experiment (Moore et al. I968), in which sheep were given daily intraruminal infusions of $18: 2$ or $18: 3$ over a period of 5 days. At the end of this period the concentrations of $18: 2$ or $18: 3$ in the plasma cholesteryl esters and phospholipids had increased, but little change was observed in the concentrations of the $\mathrm{C}_{18}$ polyunsaturated fatty acids in the plasma triglycerides. As yet, no explanation can be put forward to account for these apparently conflicting results. However, when polyunsaturated fatty acids are infused into the rumen it is reasonable to assume that, owing to hydrogenation in the rumen, smaller amounts of these acids will reach the small intestine and at a much slower rate than when the acids are infused into the abomasum. The slower rate of passage of $18: 3$ or $18: 2$ from the abomasum into the small intestine might influence the pattern of incorporation into the various plasma lipid fractions. It could also be argued that the changes in the fatty acid composition of the plasma lipid fractions observed by Moore $e t$ al. ( 1968 ) were the result of the relatively long-term intraruminal infusions of polyunsaturated fatty acids, and are, therefore, not directly comparable with the results of the present experiments, each of which involved the infusion of a single dose of polyunsaturated fatty acids into the abomasum.

The authors wish to thank Miss I. Fisher, Miss E. Skinner and Mr J. McDill for their skilled technical assistance.

\section{REFERENCES}

Duncan, W. R. H. \& Garton, G. A. (т 962). F. Lipid Res. 3, 53.

Farquhar, J. W., Insull, W. Jr, Rosen, P., Stoffel, W. \& Ahrens, E. H. Jr (I959). Nutr. Rev. I7, Suppl. Garton, G. A. (1965). In Physiology of Digestion in the Ruminant, p. 397. [R. W. Dougherty, R. S. Allen, W. Burroughs, N. L. Jacobson and A. D. McGilliard, editors.] London: Butterworth.

Garton, G. A., Lough, A. K. \& Vioque, E. (I96r). F. gen. Microbiol. 25, 2 I 5.

Heath, T. J. \& Morris, B. (1963). Br. F. Nutr. 17, 465.

Mangold, H. K. (196r). J. Am. Oil Chem. Soc. 38, 7o8. 
Moore, J. H., Noble, R. C. \& Steele, W. (r968). Br. F. Nutr. 22, 68r.

Moore, J. H. \& Williams, D. L. (1963). Can. F. Biochem. Physiol. 4x, I821.

Moore, J. H. \& Williams, D. L. (1964). Biochim. biophys. Acta 84, 4 I.

Nelson, G. J. \& Freeman, N. K. (1959). F. biol. Chem. 234, I 375.

Noble, R. C. \& Moore, J. H. (1964). Can. 7. Biochem. Physiol. 42, 1729.

Senior, J. R. (1964), F. Lipid. Res. 5, 495

Tove, S. B. \& Mochrie, R. D. (1963). F. Dairy Sci. 46, 686. 